\title{
ADOPSI PENERIMAAN DIGITAL PAYMENT PADA KALANGAN MILENIAL
}

\author{
Dian Dinata Houston \\ Program Studi Ilmu Komunikasi, Sekolah Tinggi Ilmu Komunikasi LSPR \\ E-mail : diandinatah@gmail.com
}

\begin{abstract}
Abstrak
Perkembangan teknologi yang terus berkembang dan maju membuat para aplikasi fintech berlomba-lomba untuk terus melakukan sebuah inovasi baru. Kini masyarakat bisa bertransaksi menggunakan applikasi digital payment yang dapat mempermudah kegiatan sehari-hari. Applikasi-applikasi digital payment tersebut terus melakukan inovasi-inovasi baru. Inovasi tersebut bisa berupa kemudahan dalam bertransaksi, promo-promo yang diberikan, atau fitur-fitur lain yang berhubungan dengan applikasi fintech tersebut. Adapun tujuan dari penelitian ini adalah untuk memahami sejauh mana adopsi inovasi digital payment kepada generasi millennial. Teori utama yang digunakan dalam penelitian ini ialah teori difusi inovasi yang dikemukakan oleh Everet Rogers. Metode penelitian yang digunakan ialah kualitatif dekskriptif, dengan jumlah narasumber sebanyak 10 orang yang berusia 16-22 tahun. Hasil penelitian yang diperoleh dari wawancara dengan narasumber ialah generasi millennial sudah menerima adanya inovasiinovasi baru yang diciptakan oleh applikasi-applikasi digital payment. Penggunaan applikasi digital payment dilakukan untuk berbagai hal seperti transportasi online, membeli makanan, membeli tiket, dan sebagainya.
\end{abstract}

Kata Kunci: Digital Payment, Generasi Milenial, Difusi Innovasi Perilaku Konsumen, Keputusan Pembelian

\begin{abstract}
The development of technology that continues to develop and advance makes fintech applications competing to continue to make a new innovation. Now people can transact using digital payment applications that can simplify their daily activities. The digital payment applications continue to make new innovations. These innovations can be in the form of convenience in transactions, promos provided, or other features related to the fintech application. The purpose of this study is to understand the extent of adoption of digital payment innovations to the millennial generation. The main theory used in this study is the theory of innovation diffusion proposed by Everet Rogers. The research method used is descriptive qualitative, with the number of speakers as many as 10 people aged 16-22 years. The results of the research obtained from interviews with resource persons are that the millennial generation has accepted new innovations created by digital payment applications. The use of digital payment applications is done for various things such as online transportation, buying food, buying tickets, and so on.
\end{abstract}

Key Words: Digital Payment, Millennial Generation, Diffusion of Innovation in Consumer Behavior, Purchasing Decisions 


\section{PENDAHULUAN}

Berdasarkan hasil survei data dari APJII (Asosiasi Penyelenggara Internet Indonesia) pada akhir 2018, total populasi penduduk Indonesia mencapai 264,16 juta dan akan terus bertambah. Dari 264,16 juta orang, 171,17 juta jiwa menggunakan internet. dapat dikatakan, bahwa hampir dari $65 \%$ penduduk Indonesia sudah di dominasi oleh perkembangan teknologi internet.C

Gambar 1. Data Pengguna Internet 2018

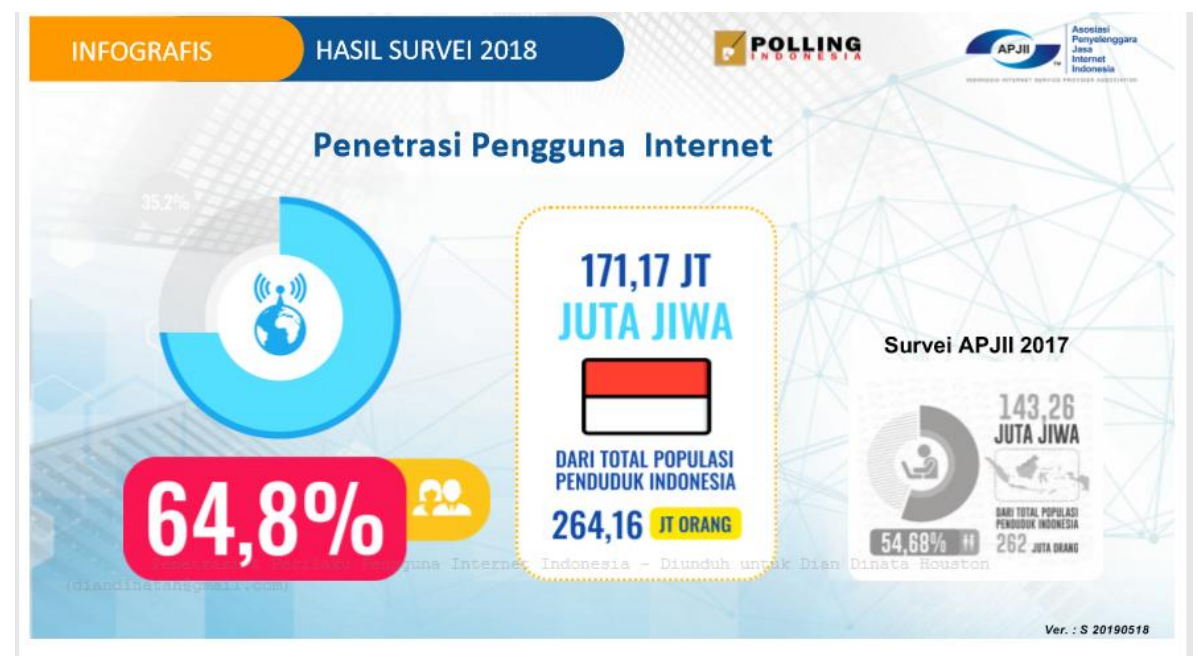

Sumber : APJII (Asosiasi Penyelenggara Internet Indonesia), p. 6-7, 2019.

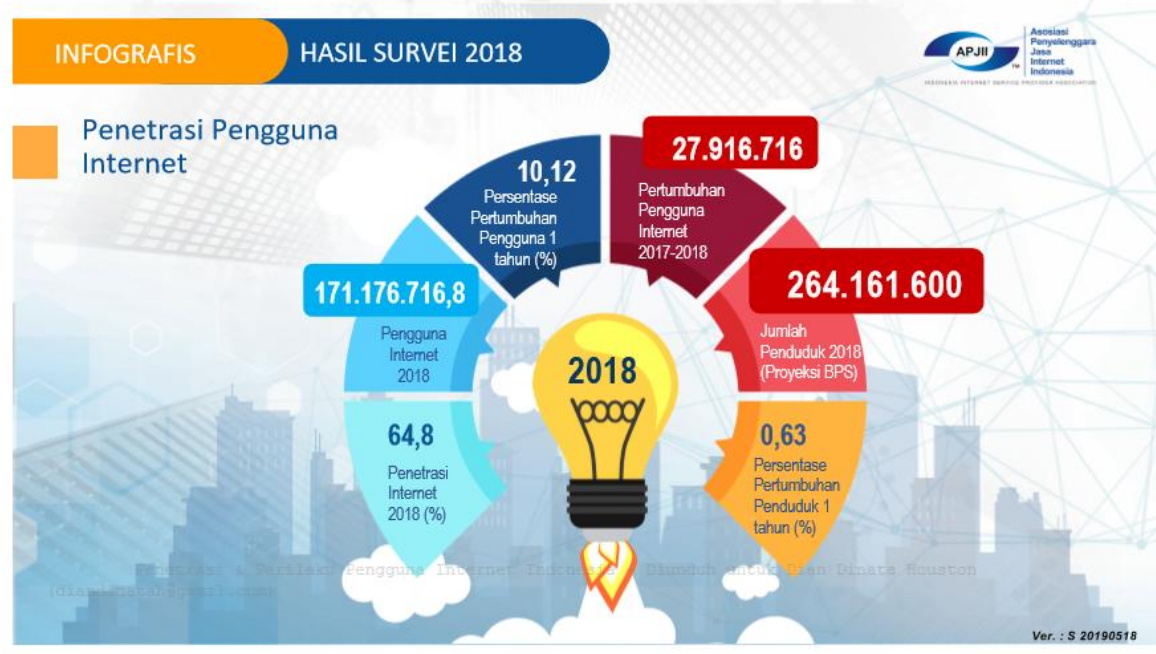

Sumber : APJII (Asosiasi Penyelenggara Internet Indonesia), p. 6-7, 2019.

Perkembangan Teknologi semakin hari semakin terus berinovasi. Secara sadar maupun tidak sadar perkembangan teknologi yang terus berinovasi tersebut merubah pola hidup masyarakat, dari segi transport, lifestyle, behavior, semua telah berubah oleh adanya perkembangan dan inovasi teknologi. Semua transaksi dapat dilakukan dengan mudah dan cepat dengan adanya perkembangan teknologi. 
Perkembangan teknologi yang terus berkembang juga terus merubah perilaku masyarakat. Perilaku masyarakat yang terus berubah secara tidak langsung menekankan kepada perkembangan teknologi. Secara sadar maupun tidak sadar, perkembangan teknologi yang terus berkembang disebabkam dengan adanya perubahan perilaku yang terus berkembang dan berinovasi. Jika perkembangan teknologi tidak melakukan pembaharuan maka akan tertinggal dengan negaranegara luar lainnya.

Perkembangan teknologi yang terus berinovasi merubah transaksi dari offline ke online ialah dengan adanya pembayaran yang dilakukan secara digital atau bisa disebut dengan digital payment.

Menurut (Katadata.co.id,2019) terdapat 37 perusahaan mobile payment yang diterbitkan oleh financial technology (fintech). Perusahaan mobile payment tidak hanya diterbitkan oleh fintech saja, tetapi juga bisa diterbitkan oleh Bank, dan perusahaan telekomunikasi. Contoh dari mobile payment yang diterbitkan oleh fintech, bank, dan perusahaan telekomunikasi ialah seperti PayTren, Ovo, Dana, Gopay, LinkAja, Sakuku, Cashbac, dsb. Dengan adanya perkembangan teknologi yang kian canggih, pembayaranpun semakin mudah dilakukan. Secara sadar maupun tidak sadar masyarakat didesak oleh perkembangan teknologi untuk cashless.

Katadata.co.id (2019), menyatakan bahwa, ada 38 dompet digital yang sudah berlisensi resmi. Hasil riset dari iPrice menyebutkan Gojek sebagai dompet digital dengan pengguna aktif bulanan terbesar di Indonesia sejak kuartal IV di tahun 2017. Lalu disusul oleh peringkat kedua yaitu OVO yang bertahan diposisi kedua selama 4 tahun berturut-turut. LinkAja sempat bersaing memperebutkan posisi kedua dari OVO. LinkAja merupakan hasil perubahan dari T-Cash dari Telkomsel. Pada kuarta II tahun 2019, posisi LinkAja berhasil digeser oleh pendatang baru, yaitu Dana yang berhasil naik ke peringkat ketiga dan LinkAja turun menjadi peringkat ke 4 . Kemudian, Jenius bertahan di peringkat kelima meskipun pada kuartal III 2018 sempat naik ke peringkat empat. Berikut hasil gambaran dari katadata.co.id (Jayani, 2019).

Gambar 3. Daftar Dompet Digital di Indonesia

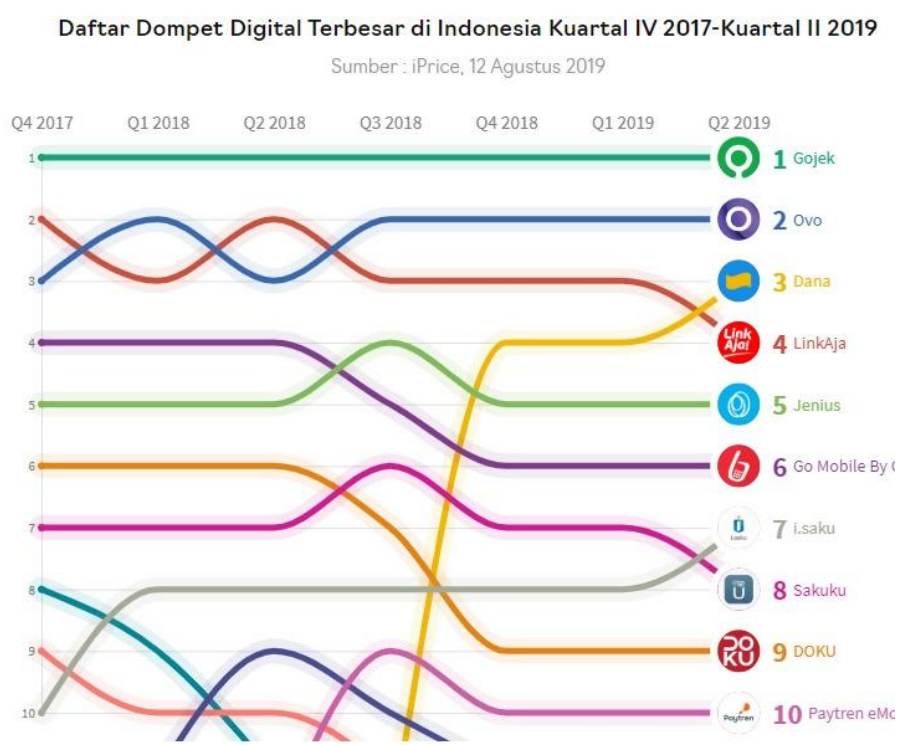


Sumber : (Jayani, 2019)

Gambar diatas menunjukan bahwa selama tahun 2017 hingga sekarang Gojek masih memimpin pasar dompet digital dan grafiknya pun stabil. Kemudian OVO dan LinkAja memiliki grafik yang naik turun, namun diungguli oleh OVO, kemudian urutan ke 3 disusul oleh applikasi fintech yang baru-baru ini booming yaitu Dana dengan \#gantidompet. Posisi ke 4 di tempati oleh LinkAja, lalu urutan ke 5 di tempati oleh Jenius by BTPN, dan seterusnya.

Saat ini penggunaan digital payment sudah mendominasi kaum generasi $\mathrm{X}, \mathrm{Y}$, dan Z. Transaksi menggunakan digital memang terbilang mudah dan praktis selain itu benefit lain dari penggunaan transaksi melalui digital payment dan fintech ialah adanya promosi-promosi yang didapatkan seperti cashback, dan diskon.

Pembayaran elektronik adalah pembayaran yang dilaksanakan secara elektronik. Di dalam pembayaran elektronik uang di simpan, di proses, dan di terima dalam bentuk informasi digital dan proses pemindahannya di inisialisasi melalui alat pembayaran elektronik. Pembayaran secara tradisional dilakukan melalui uang tunai, cek, atau kartu kredit sedangkan pembayaran elektronik dilakukan menggunakan software tertentu, kartu pembayaran, dan uang elektronnik (Trihasta \& Fajaryanti, 2008, p. 616).

Dengan latar belakang seperti yang sudah dipaparkan diatas maka hal ini menjadi menarik bagi peneliti untuk meneliti sebuah penelitian mengenai Adopsi penggunaan digital payment dikalangan anak millennial.

\section{KERANGKA TEORI}

Teori Difusi Inovasi. Teori inovasi difusi (IDT) (Rogers 2003) dalam (Juniarti, 2019) adalah dua teori adopsi inovasi utama yang telah sering diterapkan pada adopsi teknologi informasi (TI) studi secara umum, serta studi yang berfokus pada adopsi layanan seluler (Chong et al. 2012). TAM telah mampu menjelaskan dengan baik faktor-faktor yang mendorong penerapan beberapa teknologi (Bailey et al. 2017).

Model adopsi teknologi dan teori difusi inovasi dianggap sebagai model yang sesuai untuk memprediksi minat pengguna untuk mengadopsi teknologi baru. Mamun, model adopsi teknologi sering digunakan dalam studi adopsi layanan seluler karena kemudahan penerapan dan kesederhanaannya (Chong et al. 2012; Venkatesh \& Davis 2000; Zarmpou et al. 2012). Selain itu, model adopsi teknologi dapat dimodifikasi untuk memasukkan konstruksi tambahan untuk meningkatkan kekuatan prediktifnya. Berbagai versi tambahan dari teknologi adopsi teknologi telah digunakan untuk menyelidiki adopsi teknologi informasi secara umum (Chen \& Teng 2013) dalam Juniarti (2019).

Adapun 4 element dari Difusi Inovasi ialah :

1. Inovasi, Inovasi adalah ide, gagasan, pesan, makna yang dianggap baru oleh individu atau unit adopsi lainnya.

2. Communication channels, merupakan sarana komunikasi yang digunakan untuk menerima pesan dari satu orang ke lainnya. 
3. Time, Proses keputusan dimana individu beralih dari pengetahuan pertama tentang suatu inovasi melalui adopsi atau penolakannya.

4. Social Sistem, Satu set unit yang saling terkait yang terlibat dalam pemecahan masalah bersama untuk mencapai tujuan bersama.

Selain memiliki 4 element, Difusi Inovasi juga memiliki 5 bagian berdasarkan pengadopsi innovasi, berikut pembagiannya ;

1. Innovators, Innovators merupakan kelompok yangberani dan suka tantangan untuk mencoba ide baru meskipun kedepannya akan terjadi resiko. Kelompok innovators berperan penting dalam proses difusi inovasi sebagai gatekeeper atau penjaga gawang untuk menyalurkan ide-ide baru pada system social (Rogers, 2003).

2. Early Adopters, kelompok ini memiliki tingkat opinion leadership yang paling tinggi dibandingkan dengan kelompok adopter lainnya, dikarenakan memberikan saran dan informasi mengenai inovasi sebelum tahap yang lainnya (early majority ke bawah) mengadopsi inovasi tersebut. Dengan kata lain, kelompok early adopter memberikan peran testimoni untuk mengurangi keraguan dan ketidakpastian tentang ide baru tersebut (Rogers, 2003)

3. Early Majority, kelompok ini berada di tengah-tengah. Berada di awal dan berada di akhir yang mengadopsi inovasi. Kelompok ini memiliki keterkaitan dengan jaringan system social, karena mereka akan melihat testimoni dari berbagai pihak sebelum memilih untuk mengadopsinya (Rogers, 2003).

4. Late Majority, kelompok ini mengadopsi inovasi setelah yang lainnya mengadopsi terlebih dahulu. Kelompok ini akan mengadopsi inovasi baru setelah semua keraguannya mengenai inovasi tersebut hilang dan merasa bahwa inovasi ini aman untuk digunakan (Rogers, 2003).

5. Laggards, kelompok ini merupakan kelompok tradisional karena tidak memiliki opinion leader, dan kebanyakan terisolasi dari jaringan social. Kelompok ini biasanya memutuskan untuk mengadopsi inovasi berdasarkan pengalaman dari generasi-generasi sebelumnya yang memberikan masukan bahwa inovasi ini aman untuk digunakan dan dipakai (Rogers, 2003).

Process of Innovation Development. Menurut (Rogers, 2003) proses perkembangan inovasi terdiri dari beberapa step diantaranya terdiri dari keputusan, aktivitas, dan dampak yang terjadi akibat dari masalah dari sebuah inovasi tersebut. Berikut figure dari perkembangan inovasi yang dipaparkan oleh Rogers. 
Gambar 4. Proses Perkembangan Inovasi

\begin{tabular}{|c|c|c|c|c|c|}
\hline $\begin{array}{ll}\text { INITIATION } \begin{array}{l}\text { Inf } \\
\text { cor }\end{array}\end{array}$ & $\begin{array}{l}\text { tion gathering, } \\
\text { ualizing and planning. }\end{array}$ & DECISION & IMPLEMENTATION & $\begin{array}{l}\text { All events, actions, decision } \\
\text { innovation into use. }\end{array}$ & olved with putting an \\
\hline $\begin{array}{l}\text { 1. NEEDS/ } \\
\text { PROBLEMS }\end{array}$ & 2. RESEARCH & 3. DEVELOPMENT & $\begin{array}{l}\text { 4. COMMERCIAL- } \\
\text { IZATION }\end{array}$ & $\begin{array}{l}\text { 5. DIFFUSION } \\
\text { AND ADOPTION }\end{array}$ & 6. CONSEQUENCES \\
\hline $\begin{array}{l}\text { Recognition or } \\
\text { inquiry into a } \\
\text { condition or } \\
\text { situation that } \\
\text { requires } \\
\text { investigation and } \\
\text { resolution. }\end{array}$ & $\begin{array}{l}\text { Original } \\
\text { investigations } \\
\text { for knowledge } \\
\text { production or } \\
\text { to solve } \\
\text { practical } \\
\text { problems. }\end{array}$ & $\begin{array}{l}\text { The process of } \\
\text { putting a new } \\
\text { idea in a form } \\
\text { that is expected } \\
\text { to meet the needs } \\
\text { of potential } \\
\text { adopters. }\end{array}$ & $\begin{array}{l}\text { The production, } \\
\text { manufacturing, } \\
\text { packaging, } \\
\text { marketing, and } \\
\text { distribution of } \\
\text { a product } \\
\text { that embodies } \\
\text { an innovation. }\end{array}$ & $\begin{array}{l}\text { The crucial } \\
\text { decision in the } \\
\text { entire process to } \\
\text { begin diffusing } \\
\text { the innovation } \\
\text { to potential } \\
\text { adopters. }\end{array}$ & $\begin{array}{l}\text { The original } \\
\text { problem/need } \\
\text { that began } \\
\text { the entire process } \\
\text { either is or is not } \\
\text { solved by the } \\
\text { innovation. }\end{array}$ \\
\hline
\end{tabular}

Adapted from: Rogers Everett, M. (1995). Diffusion of innovations. New York. pp:133

Sumber : Rogers, 2003, p. 133

1. Needs/Problem, pada tahap ini perkembangan inovasi timbul kesadaran atau keinginan dari suatu masalah yang mendorong untuk menciptakan pembaruan atau inovasi untuk memecahkan masalah tersebut (Rogers, 2003)

2. Research, pada tahap ini perkembangan inovasi dimulai dari memecahkan masalah. Masalah yang terjadi ialah teknologi (Rogers, 2003)

3. Development, penelitian dan pengembangan merupakan dua hal yang tidak dapat dipisahkan. Pengembangan inovasi merupakan proses terjadinya inovasi baru kedalam bentuk yang diharapkan agar memenuhi kebutuhan adopter (Rogers, 2003)

4. Commercialization, pada tahap ini menjelaskan bahwa inovasi adalah hasil dari aktivitas penelitian yaitu hasil yang siap untuk diadopsi oleh pengguna. Commercialization sendiri artinya adalah proses produksi, manufaktur, pengemasan, marketing, dan distribusi produk yang menjadikan sebuah inovasi (Rogers, 2003).

5. Diffusion and Adoption, pada proses perkembangan inovasi tahap yang paling penting ialah keputusan untuk menyebarkan inovasi pada adopter. Inovasi dapat diterima atau ditolak oleh adopter berdasarkan evaluasi mereka pada saat uji klinis yang diadakan ditahap commercialization pada proses perkembangan inovasi. Tujuan dari uji klinis adalah untuk mengevaluasi inovasi tersebut pada kehidupan nyata, untuk mengambil keputusan, dan untuk menyebarkan inovasi. Komunikasi berperan penting dalam tahap difusi dan adopsi (Rogers, 2003).

6. Consequences, ini adalah tahap akhir dari proses perkembangan inovasi. Pada tahap ini dijelaskan mengenai konsekuensi dari inovasi dimana masalah awal yaitu keinginan yang memulai proses secara keseluruhan dapat atau tidak dapat dipecahkan oleh inovasi yang ditawarkan (Rogers, 
2003).

Teori Perilaku konsumen. Menurut Schiffman dan Kanuk (1994) dalam bukunya yang berjudul Consumer Behavior mendefinisikan sebagai perilaku yang diperlihatkan konsumen dalam mencari, membeli, menggunakan, mengevaluasi dan menghabiskan produk dan jasa yang mereka harapkan akan memuaskan kebutuhan mereka.

Adapun menurut (Solomon 2017) : Studi perilaku konsumen merupakan proses ketika individu atau kelompok menyeleksi, membeli, menggunakan atau membuang produk, pelayanan, ide, dan pengalaman untuk memuaskan kebutuhannya (Sudaryono, 2014, pp. 5-6).

Winardi (1991) berpedendapat bahwa perilaku konsumen dapat dirumuskan sebagai perilaku yang ditunjukkan oleh orang - orang dalam hal merencanakan, membeli dan menggunakan barang - barang ekonomi dan jasa - jasa (Sudaryono, 2014, p. 8)

Perilaku Konsumen sangat berpengaruh bahkan sangat menguntungkan dengan mengetahui sikap seseorang dimana dalam hal ini diketahui bahwa perusahaan dapat mengetahui apa yang diinginkan atau dibutuhkan dari seorang pelanggan agar dapat memenuhi kebutuhan dari perusahaan tersebut, karena dari itu perusahaan perlu tahu seperti apa sikap dari seorang pelanggan untuk dapat memuaskan kebutuhannya. Seperti apa yang diutarakan oleh (Sudaryono, 2014, p. 11) bagi para pelaku usaha memahami perilaku konsumen merupakan landasan yang sangat penting guna menyusun strategi pemasaran dan operasionaissasi cara penjualan. Dengan memahami perilaku konsumen, pelaku usaha akan mampu mengelompokkan konsumen berdasarkan gender, berdasarkan usia, berdasarkan tingkat Pendidikan, dan berdasarkan jenis pekerjaan.

Perilaku konsumen yang menerangkan bahwa keputusan pembelian selain dipengaruhi olehkarakteristik konsumen, dapat dipengaruhi oleh bauran pemasaran yang mencakup produk, harga, distribusi, dan promosi. Variabel-variabel tersebut di atas saling mempengaruhi proses keputusan pembelian sehingga menghasilkan keputusan pembelian yang didasarkan pada pilihan produk, pilihan merk, pilihan penyalur, pilihan waktupembelian, jumlah pembelian (Kotler, 2007).

Menurut Schiffman dan Manuk (1994), ada beberapa tahapan - tahapan langkah dalam perilaku konsumen yang ditempuh dan dilakukan oleh seseorang atau individual atau kelompok orang dalam rangka memebuhi kebutuhan dan keinginannya, yaitu: (Sudaryono, 2014, pp. 6 - 7)

1. Need Recognition (mengenali kebutuhan)

2. Pre-purchase search (mencari informasi sebelum membeli)

3. Purchase trial and repeat purchase (melakukan pembelian dengan cara mencoba - coba dan melakukan pembelian ulang)

4. Post purchase evaluation (melakukan evaluasi pascabeli) 
Menurut Danang Sunyoto (2013) (Sudaryono, 2014, pp. 18-19), ada tiga variable dalam perilaku konsumen, yaitu variable stimulus, variable respons dan variable antara. Hal ini sesuai dengan pendapat David L.London dan Albert J. Della Bitta (1984) dalam Anwar prabu Mangkunegara (1998) mengemukakan bahwa : Three classes of variabels are involved in understanding consumer behavior in any of these specific situation: stimulus variabels, response variable, and intervening variabels. (Sudaryono, 2014, p. 18)

1. Variable stimulus : variable yang berada di luar diri individu (factor eksternal) yang sangat berpengaruh dalam proses pembelian. Contohnya, merek dan jenis barang, iklan, pramuniaga, penataan barang, dan ruangan toko.

2. Variable respons : hasil aktivitas individu sebagai reaksi dari variable stimulus. Variable respons sangat bergantung pada factor individu dan kekuatan stimulus. Contohnya, keputusan membeli barang, pemberi penilaian terhadap barang, dan perubahan sikap terhadap suatu produk.

3. Variable intervening : variabel antara stimulus dan respons. Variable ini merupakan factor internal individu, termasuk motif - motif membeli, sikap terhadap suatu peristiwa, dan persepsi terhadap suatu barang. Peranan variable intervening adalah untuk memodifikasi respons.

Menurut Sujoto (2009:60) mengatakan ada 2 kelompok faktor yang mempengaruhi perilaku konsumen: (Prisgunanto, 2014, pp. 173 - 174)

1. Sifat Individual

a. Faktor kebudayaan, perilaku setiap orang sangat dipengaruhi oleh kebudayaan dimana mereka hidup dan tinggal.

b. Faktor sosial, perilaku seseorang ditentukan oleh berbagai faktor social seperti keanggotaannya dalam kelompok social, keluarga, dan kedudukannya di masyarakat.

c. Faktor orang perorangan, perilaku seseorang ditentukan berbagai faktor pribadi atau individual, seperti usia, gender, pekerjaan, dan jumlah penghasilan tetap.

d. Faktor psikologis, perilaku konsumen dipengaruhi oleh 3 macam faktor psikologis yakni; motivasi, persepsi, dan kepercayaan diri.

2. Proses pengambilan keputusan

Proses pengambilan keputusan ditentukan oleh 5 tahap;

a. Pengenalana kebutuhan, rasa membutuhkan sesuatu yang disebabkan dorongan untuk membeli suatu produk apabila mendapat pengaruh dari luar diri konsumen.

b. Pencarian alternative informasi, intensitas upaya konsumen untuk mencari informasi tentang produk yang mereka butuhkan.

c. Penilaian terhadap berbagai macam informasi yang terkumpul, mempergunakan informasi tentang berbagai macam produk yang berhasil mereka butuhkan sebagai bahan pertimbangan untuk menjatuhkan pilihan pada produk dan merek dagang tertentu. 
d. Keputusan untuk membeli, bila tidak ada faktor - faktor lain yang mempengaruhinya biasanya konsumen membeli produk dengan merek tertentu yang menjanjikan paling banyak atribut yang dianggap sesuai dengan kebutuhan dan keinginan mereka.

e. Evaluasi sesudah pembelian, pengalaman konsumen setelah menggunakan produk yang memberikan pengaruh dalam pengambilan keputusan untuk membeli lagi produk yang sama saat mereka membutuhkannya lagi.

E-Payment. Pembayaran elektronik bermula saat perkembangan juga ecommerce. Perkembangan yang pesat saat e-commerce terjadi membuat beberapa kalangan untuk mengembangkan suatu produk baru yang mampu membantu kelancaran proses transaksi e-commerce. Karena e-commerce bekerja secara online, maka produk pendukungnya pun juga berbasis online. Akhirnya muncul system baru pembayaran secara online yang disebut dengan e-payment. E-payment adalah suatu system yang menyediakan alat - alat untuk pembayaran jasa atau barang barang yang di lakukan di internet (secara online). E-payment biasanya di gunakan suatu perusahaan dengan menjalin kerja sama dari sejumlah lembaga perbankan. Seiring berkembangnya e-payment yang di gunakan sesuai kebutuhan suatu perusahaan maka berkembanglah beberapa macam bentuk sistem pembayaran EPayment antara lain. E-Wallet, E-Cash, electronic cheque, smartcard (Nugroho, 2018).

Generasi Millenial. Generasi millenial adalah yang lahir pada rentang tahun 1980 - 2000. Ada dua generasi yang lahir sebelum generasi millenial, yaitu generasi baby boomers dan generasi X. Generasi millenials ini penuh dengan ide visioner, inovatif, memanfaatkan teknologi, dan mementingkan prestasi kerja. Generasi millenial mempunyai sebutan lain yaitu generasi Y atau echo boomers. Generasi ini tumbuh pada abad milenium 2000, seiring dengan perkembangan teknologi informasi dan internet yang secepat Flash mengubah wajah dunia (MarComm, 2018, pp. 9 - 11).

Penelitian Graham Brown menyebutnya dengan istilah "Mobile Generation". Karena istilah 'generasi milenial' adalah istilah yang paling umum juga lebih sesuai dengan konteks penelitian, peneliti memakai istilah generasi milenial untuk mendeskripsikan generasi yang lahir pada era informasi dimana teknologi media berkembang dan menyatu dengan kehidupan sehari-hari (Damajanti \& Siregar).

\section{METODE PENELITIAN}

Dalam penelitian ini penulis ingin mendapatkan hasil yang mendalam dan representatif, sehingga penulis menggunakan metode kualitatif deskriptif. Menurut Sutopo dan Arief dalam (Suwendra, 2018, p. 5) menyimpulkan beberapa pendapat pakar tentang pengertian kualitatif adalah : "(1) mendeskripsikan dan menganalisis fenomena, peristiwa, aktivitas social, sikap, kepercayaan, persepsi, pemikiran orang secara individual maupun kelompok. (2) kegiatan terencana untuk menangkap praktek penafsiran responden atau informan terhadap dunianya (emik atau versetehen) yang selalu majemuk, berbeda dan dinamis. (3) bersifat menggambarkan, mengungkapkan, dan menjelaskan".

Menurut Ruslan (2010, p. 12), Penelitian secara deskriptif menggambarkan mengenai karakteristik individu, situasi dan kelompok tertentu. Penelitian kualitatif memiliki hubungan - hubungan di antara gejala, atau satuan individual atau unsur - 
unsur dipahami. Pemahaman dilakukan dengan cara melihat hubungan - ubungan tersebut dari perspektif yang diteliti (Patilima, 2007, p. 5)

Melalui penelitian ini, kajian yang digunakan untuk dapat mengetahui penggunaan digital payment dikalangan anak millennial menggunakan metode wawancara. Dimana metode wawancara sendiri merupakan percakapan dengan maksud tertentu. Percakapan itu dilakukan oleh kedua belah pihak yaitu pewawancara yang memberikan pertanyaan dan terwawancara yang memberikan jawaban.

Menurut Lincoln dan Guba (1985:266) maksud mengajukan wawancara adalah untuk mengonstruksi mengenai orang, kejadian, organisasi, perasaan, motivasi, tuntutan, dan lain-lain. Serta memverifikasi, mengubah, dan memperluas informasi yang diperoleh dari orang lain baik manusia maupun bukan manusia (triangulasi), dan memverifikasi, mengubah, dan memperluas konstruksi yang dikembangkan oleh peneliti sebagai pengecekan anggota. (Moleong, 2017, p. 186)

Adapun yang menjadi narasumber peneliti adalah 10 generasi millennial yang berusia 16-22 tahun yang terjadi dari 5 orang perempuan dan 5 orang laki-laki. ke 10 narasumber tersebut merupakan pengguna digital payment untuk kegiatan sehari-harinya.

\section{HASIL DAN PEMBAHASAN}

Berdasarkan dari hasil wawancara yang sudah dilakukan, ke 10 orang narasumber peneliti sudah mengetahui berbagai jenis applikasi digital payment dan bebeapa dari mereka sudah memiliki semua applikasi digital payment yang beredar (Gojek, Ovo, Dana, Shopee Pay, Cashbac, dsb). Pengunaan digital payment kini sudah marak dan semakin mudah digunakan, selain mempermudah pengguna, digital payment juga memberikan benefit lainnya yaitu dengan memberikan diskon, cashback yang membuat pengguna tertarik untuk menggunakannya. Saat ini penggunaan internet sudah cukup luas siapapun pasti memakainya terutama generasi milenial yang dimana sudah mulai "melek" teknologi. Setiap perusahaan fintech berbondong-bondong untuk memperbarui fitur dari digital payment agar bisa diterima oleh masyarakat luas dan diakses oleh pengguna. Saat ini menurut hasil research dan hasil diskusi peneliti dengan beberapa narasumber, target utama dari perusahaan-perusahaan fintech ialah millennial. Perusahaan fintech berlomalomba untuk mempercantik fitur-fitur yang ada dalam applikasi tersebut, mempercantik mempromosikan applikasi fintech tersebut agar menjadi pilihan utama konsumen dalam bertransaksi. Dengan menggunakan digital payment semua urusan bisa dilakukan dengan mudah dalam bertransaksi tanpa perlu direpotkan dengan metode pembayaran cash alias tunai. Menurut 10 narasumber yang diantaranya adalah kaum milenial mengatakan mereka sudah mengetahui tentang digital payment dan mereka sudah menggunakan metode pembayaran tersebut kurang lebihnya selama 2 hingga 4 tahun belakangan ini. Digital payment yang mereka gunakan antara lain adalah OVO, Dana, dan Go-Pay dimana alat transaksi tersebut paling banyak digunakan. Adapun kelebihan dan kekurangan dari digital payment pun sangat berbagai macam jawabannya diantaranya mengatakan kelebihan dari lebih murah dan cash less atau efisien sehingga pengguna tidak harus mempunyai uang tunai, sewaktu diperlukan tidak perlu susah lagi mencari mesin ATM karena bisa menggunakan aplikasi langsung, dapat mempermudah aktivitas sehari - hari, bisa digunakan dimana saja karena sudah banyak toko yang telah 
menggunakan Go-Pay untuk system pembayarannya sedangkan kekurangan dari digital payment belum bisa di gunakan di semua tempat hanya beberapa tempat tertentu saja karena tempat tersebut belum support menggunakan Go-Pay, OVO, Dana, Shopee Pay, Cashbac hanya bisa digunakan untuk pembayaran tertentu saja, aplikasi kurang aman, sering kali terjadi penipuan karena akun teretas atau hack. Tak hanya itu, terkadang saat akan digunakan untuk order Go-Food/Go-Ride saldo akan terpotong sedangkan orderan belum diterima atau telah dihentikan oleh driver dengan sendirinya, kemudian dalam melakukan pengisian saldo melalui ATM biasanya dikenakan biaya admin, kebutuhan pada akses internet jika koneksi internet gagal maka tidak akan bisa mengakses akun digital paymet tersebut. Semua (10) narasumber mengatakan mereka memilih digital payment karena bisa digunakan untuk memesan ojek online tanpa perlu menggunakan cash atau uang tunai, pada aplikasi ini juga selalu memberikan harga yang relatif lebih murah dibandingkan dengan aplikasi lain ataupun uang tunai, lebih mudah dan banyak promo yang di tawarkan dengan melalui digital payment seperti tiket bioskop, membeli kopi, bertransaksi di mini market konvensional seperti family mart, alfamart juga mendapatkan cashback, berbelanja di supermarket tertentu yang bekerja sama dengan fntech tersebut juga mendapatkan cashback seperti hypermart, farm market, transmart. Berbelanja buku d toko Gramedia juga mendapatkan diskon 20\% jika pembayaran menggunakan Go-Pay. Alasan lainnya yang di dapatkan dari penggunaan digital payment adalah karena cashless dan praktis yang didapatkan sehingga memudahkan dalam setiap bertransaksi dan jauh lebih mudah untuk digunakan dalam kegiatan sehari - hari, sebagai alat transport, membeli makanan maupun minuman dan juga sebagai alat pembayaran ketika bertransaksi. Rata - rata dari mereka juga mengisi ulang saldo tersebut sekitar Rp.100.000 - Rp. 400.000 /bulan. Menurut ke-10 narasumber tersebut rata -rata mengatakan bahwa penggunaan digital payment ini sangat mempermudah, namun sering kali digital payment memotong saldo dengan pecahan kecil yang tidak bisa diakumulasi seperti Rp750,- Rp. 250,- ataupun dibawah seribu rupiah.

Dengan digunakannya applikasi fintech digital payment ini, menandakan bahwa masyarakat ginerasi millennial sudah menerima adanya inovasi baru yaitu penggunaan digital payment dalam bertransaksi. Tentu diterima atau tidak diterimanya sebuah inovasi bergantung pada perilaku masing-masing individu. Selain mempengaruhi perilaku individu, digital payment juga mempengaruhi keputuasan untuk bertransaksi. Dimana keputusan bertransaksi tersebut terjadi ketika konsumen sudah setuju dengan apa yg akan di beli atau dipesan. Keputusan bertransaksi merupakan sebuah proses pengambilan keputusan apakah konsumen akan membeli atau tidak membeli. Dengan adanya digital payment yang bisa digunakan dan lakukan dimanapun dan kapanpun tentu sangat mempengaruhi keputusan pembelian. Kalangan millenial sangat suka sekali dengan yang namanya instan. Dengan adanya digital payment yg ada seperti OVO, Go-Pay, Dana, Cashbac Shopee Pay, dll ini sangat membantu proses pembayaran dan bertransaksi secara online dan offline. Konsumen tidak perlu lagi datan ke gerai atm atau ke bank untuk melakukan pembayaran. Pembayaran cukup di lakukan dimanapun dan kapanpun selama saldo dari applikasi digital payment tersebut tersedia. Keputusan bertransaski tentu sangat mempengaruhi perilaku konsumen. Perilaku konsumen merupakan perilaku yg diperlihatkan oleh konsumen untuk mencari, membeli, menggunakan, mengevaluasi, dan menghabiskan prodcuk atau jasa yg diharapkan dan dpt memuaskan kebutuhan mereka (Schiffman dan Kanuk 1994). 
Proses pengambilan keputusan dalam hal bertransaksi juga dipengaruhi oleh adanya innovasi yang diciptakan oleh applikasi-applikasi fintech tersebut. Dimana penggunaan digital payment lebih mudah dan efisien serta efektif ditambah dengan penggunaan digital payment yang bisa dilakukan dimanapun dan kapanpun, meskipun penggunaan digital payment sendiri memiliki berbagai kekurangan seperti kurang aman karena masih sering kali terjadi teretas atau hack, belum semua tempat dapat menerima pembayaran menggunakan digital payment, bergantung kepada sinyal handphone, dan lain sebagainya tetapi tetap saja perilaku konsumen khususnya generasi milenial masih tetap memilih menggunakan digital payment dikarenakan banyak promo yang di dapat, lebih murah, bisa digunakan dimanapun dan kapanpun, efisien, dan lain sebagainya.

\section{KESIMPULAN}

Perkembangan teknologi yang terus berkembang dan terus maju yang menghasilkan sebuah inovasi baru yaitu pembayaran yang dapat dilakukan secara online dan melalui smartphone membuat generasi millennial lebih memilih bertransaksi menggunakan digital payment dibandingkan dengan uang tunai. Bertransaksi menggunakan digital payment selain efektif dan efisien, juga banyak keuntungan lain yang didapat yaitu banyak mendapatkan promo-promo menarik lainnya seperti cashback dan diskon sehingga lebih hemat.

\section{DAFTAR PUSTAKA}

Asosiasi Penyelenggara Jasa Internet Indonesia (n.d). Statistik. Diakses pada (27 Desember 2019), Diperoleh dari:https://apjii.or.id/content/read/39/410/Hasil-Survei-Penetrasi-danPerilaku-Pengguna-Internet-Indonesia-2018

Bailey, A.A. et al., 2017. Mobile payments

adoption by US consumers: an extended TAM. International

Chong, A.Y. -L., Chan, F.T.S. \& Ooi, K.-B.,

2012. Predicting consumer decisions to adopt mobile commerce: Cross country empirical examination between China and Malaysia. Decision Support Systems, 53, pp.34-43.

Katadata.co.id (12 Agustus 2019, Daftar

Dompet Digital Terbesar di Indonesia. Diakses pada (28 Januari 2019), Diperoleh dari : https://databoks.katadata.co.id/datapublish/2019/08/23/inilahdaftar-dompet-digital-terbesar-di-indonesia

Kotler, P. (2007). Manajemen Pemasaran. Jakarta: PT Indeks Kelompok Gramedia.

MarComm, M. (2018). Millennials. Jakarta: Fantasious x Loveable.

Moleong, J. L (2017). Metodologi

penelitian kualitatif. Bandung,

Indonesia : PT Remaja Rosdakarya 
Nugroho, A. (2018). Regulasi Terkait Pembayaran Elektronik Di Indonesia. 6 - 7.

Patilima, H. (2007). Metode Penelitian Kualitatif . Bandung: ALFABETA.

Prisgunanto, I. (2014). Komunikasi Pemasaran Era Digital. Jakarta: CV.Prisani Cendekia.

Rogers, M. E., (2003). Diffusion of Innovation Fifth Edition, America, New York : Simon \& Schuster, Inc.

Ruslan, R. (2010). Metode penelitian:

Public Relation dan Komunikasi.

Jakarta, Indonesia: PT Raja Grafindo Persada.

Schiffman, L. G., \& Kanuk, L. L. (2008).

Consumer Behavior, New Jersey : Prentice-Hall, Inc

Sudaryono. (2014). Perilaku Konsumen. Jakarta Pusat: Lentera Ilmu Cendekia.

Suwendra, W. I (2018). Metodologi

Penelitian Kualitatif Dalam Ilmu

Social, Pendidikan, Kebudayaan Dan Keagamaan. Bali, Indonesia: Nilacakra

Trihasta, D., \& Fajaryanti, J. (2008). “E-payment” SISTEM . 616.

Venkatesh, V. \& Davis, F.D.., 2000. A

theoretical extension of the technology acceptance model: Four longitudinal field studies. Management Science, 46, pp.186-204.

Zarmpou, T. et al., 2012. Modeling users'

acceptance of mobile services. Electronic Commerce Research and Applications, 12, pp. 225-248. 